\title{
Hybrid ionic plastic crystals in the race for enhanced low-pressure barocaloric materials.
}

\author{
Jorge Salgado-Beceiro, ${ }^{\text {ał }}$ Juan Manuel Bermúdez-García ${ }^{\mathrm{a}, \mathrm{b}, \neq,{ }^{,},}$, Enric Stern-Taulats, ${ }^{\mathrm{b}}$ Javier García-Ben, ${ }^{\text {a Socorro }}$ \\ Castro-García, ${ }^{\mathrm{a}}$ Manuel Sánchez-Andújar, ${ }^{\mathrm{a}}$ Xavier Moya, ${ }^{\mathrm{b},{ }^{* *}}$ and María Antonia Señarís-Rodríguez ${ }^{\mathrm{a},{ }^{* * *}}$
}

a. University of A Coruna, QuiMolMat Group, Dpt. Chemistry, Faculty of Science and Advanced Scientific Research Center (CICA), Zapateira, 15071 A Coruña, Spain.

b. University of Cambridge, Department of Materials Science, Cambridge CB3 OFS, United Kingdom.

$\ddagger$ These authors have equally contributed to this work.

*j.bermudez@udc.es, **xm212@cam.ac.uk,***m.senaris.rodriguez@udc.es

In this work, we introduce a new family of barocaloric hybrid organic-inorganic compounds with colossal barocaloric effects. The here reported hybrid materials, $\left[\left(\mathrm{CH}_{3}\right)_{3}\left(\mathrm{CH}_{2} \mathrm{Cl}\right) \mathrm{N}\right] \mathrm{FeCl}_{4}$ and $\left[\left(\mathrm{CH}_{3}\right)_{3} \mathrm{~S}\right] \mathrm{FeCl}$, exhibit a molecular structure composed by discrete inorganic anions and organic cations with weak elestrostatic interactions. Our calorimetric studies reveal colossal barocaloric effects of similar magnitude than organic plastic crystals $\left(\Delta S>100 \mathrm{~J} \mathrm{~K}^{-1} \mathrm{~kg}^{-1}\right.$ ) near room temperature and under smaller pressures ( $p \leq 1000$ bar), which leads to higher barocaloric strengths. Furthermore, these materials exhibit densities similar to barocaloric hybrid perovskites enhancing the volumetric barocaloric effects $\left(\Delta S \sim 200 \mathrm{~J} \mathrm{~K}^{-1} \mathrm{I}^{-1}\right.$ ), which could provide more compact cooling devices. Therefore, the colossal values of the mass and volumetric barocaloric effects and large barocaloric strength, in addition to the low working pressure and near-room-temperature operation, offer a new family of compounds (that of ionic hybrid plastic crystals) to further explore in the search for improved barocaloric materials. This is of great interest since barocalorics have been proposed as strong candidates to reach zero-emission target by 2050, providing they can reduce their operating pressures, which traditionally are over 1000 bar.

\section{Introduction.}

In the last years, the field of solid-state refrigeration has experienced a race for the discovery of the best barocaloric materials that could be viable for commercial implementation. As a matter of fact, the 2020 Henry Royce Institute's road map "materials for the energy transition" postulates the emerging barocaloric materials as a promising tool that would help to reach the target of net zero-emissions by $2050 .^{1}$

Accordingly, solid-state barocaloric refrigeration arises as a promising alternative to the ubiquotous vapour-compresion systems, which use hazardous gases with environmental, efficiency and safety concerns (including greenhouse effect, fluid-originated thermal losses, toxicity, and/or flammability). ${ }^{2-5}$ Barocaloric materials are solid-state compounds that can also provide refrigeration under a compression cycle, and avoid the latter concerns. ${ }^{6-8}$ For a solid-state compound to be considered a good barocaloric, it should fulfill certain characteristics, specially: near-room-temperature phase transition, associated extremely large entropy changes, and easy-achievable operating pressures to avoid irreversible thermal losses. ${ }^{9-12}$ In a first approximation, the ideal barocaloric material for commercial refrigeration would display colossal thermal changes (barocaloric effects of $\Delta S>100 \mathrm{~J} \mathrm{~K}^{-1} \mathrm{~kg}^{-1}$ ) near ambient temperature (from $\sim 315 \mathrm{~K}$ down to $\sim 273 \mathrm{~K}$, or even lower in the case of freezing devices), and under the application of pressures well-below 1000 bar. $^{1}$ Thus, it is primordial to find materials with colossal and reversible isothermal entropy changes, $\Delta S_{\text {rev }}$, (and adiabatic temperature changes, $\Delta T_{\text {rev }}$ ), large barocaloric coefficient $\left(\mathrm{d} T_{\mathrm{t}} / \mathrm{d} p\right)$ and strength $\left(\Delta S_{\text {rev }} / \Delta p\right)^{13}$ (sensitivity to pressure) and appropiate operating temperature $\left(T_{\mathrm{op}}\right)^{14}$, which is the thermal region where the barocaloric effect can be reversibly induced.

In the search for new materials that could fulfil those requirements, we found the first barocaloric materials operating under pressures easily-achievable by commercial compressors. As a matter of fact, we reported the barocaloric hybrid organic-inorganic perovskites $[\mathrm{TPrA}] \mathrm{M}[\mathrm{dca}]_{3}\left(\mathrm{M}=\mathrm{Mn}^{2+}\right.$ and $\left.\mathrm{Cd}^{2+}\right)$ that can operate under pressures as small as 70 bar near ambient temperature. ${ }^{13,15,16}$ However, their barocaloric effects, although with values considered as giant $\left(\left|\Delta S_{\text {rev }}\right|=[10-40] \mathrm{J} \mathrm{K}^{-1} \mathrm{~kg}^{-1}\right)$, were still far from the mentioned colossal magnitude. Soon after that, we reported another hybrid perovskite, $\left[\left(\mathrm{CH}_{3}\right)_{4} \mathrm{~N}\right] \mathrm{Mn}\left[\mathrm{N}_{3}\right]_{3}$, with improved near-colossal barocaloric effects $\left(\left|\Delta S_{\text {rev }}\right| \sim 70 \mathrm{~J} \mathrm{~kg}^{-1} \mathrm{~K}^{-1}\right)$ at the expense of increasing the operating pressure at 900 bar. ${ }^{12}$ The giant barocaloric effects in these hybrid perovskites are related to the large structural disordering when undergoing the pressure-induced order-disorder phase transition. However, their crystal structures are formed by 3D-frameworks linked by strong chemical bonds, which limits the aforementioned disordering and, consequently, the magnitude of the barocaloric effects.

Even more recently, this limitation has been overcome in a long-known family of molecular organic plastic crystals, ${ }^{17-19}$ which exhibit weaker chemical bonds. Therefore, these molecular compounds exhibit plastic crystal behaviour with extremely large disordering across the order-disorder phase transition. Up-to-date, these compounds exhibit record colossal barocaloric effects. A very remarkable example is neopentylglycol (NPG) with a value of $\left|\Delta S_{\text {rev }}\right| \sim 445 \mathrm{~J} \mathrm{~kg}^{-1} \mathrm{~K}^{-1}$ at $311 \mathrm{~K}$. However, this material requires operating pressures above 2500 bar, which hinders its commercial applications. ${ }^{17}$ This large pressure requirement has been recently reduced in another family of also long-known molecular organic plastic crystals, 1 -haloadamantanes, ${ }^{20}$ which exhibit 
reversible barocaloric effects of $\left|\Delta S_{\text {rev }}\right| \sim 153 \mathrm{~J} \mathrm{~K}^{-1} \mathrm{~kg}^{-1}$ under pressures of 1000 bar. However, these materials exhibit a low density that decreases the barocaloric effects per unit of volume, which would imply more bulky refrigeration devices. In addition, 1-haloadamantanes have been reported to react with fluids that contain hydroxil groups (including typical heat-exchange fluids, such as ethyleneglycol), which could generate corrosive acids. ${ }^{21}$

In this work, we aim to combine the advantages of all the above mentioned materials, and we explore the barocaloric effects in an emerging family of hybrid organic-inorganic materials with molecular (instead of 3D-framework) structure and plastic crystal behaviour. In particular, we focus on the $\left[\left(\mathrm{CH}_{3}\right)_{3}\left(\mathrm{CH}_{2} \mathrm{Cl}\right) \mathrm{N}\right] \mathrm{FeCl}{ }_{4}(\mathbf{1})$ and $\left[\left(\mathrm{CH}_{3}\right)_{3} \mathrm{~S}\right] \mathrm{FeCl}_{4}(\mathbf{2})$ compounds, which have been recently reported as multifunctional compounds with interesting magnetic and electric properties, as well as thermal energy storage. 22,23 These hybrids contain polyatomic organic (alkylammonium) cations and polyatomic inorganic (tetrachloroferrate) anions, while maintaining the molecular nature of the organic plastic crystals. The presence of weak chemical interactions between the ionic building-blocks allows for a large pressure responsiveness and barocaloric coefficient. At the same time, this pressure responsiveness is enhanced by the soft nature of organic components, meanwhile the inorganic components increase the materials density that allows for a larger volumetric barocaloric effect.

\section{Results and discussion.}

In this work, we synthesized the hybrid ionic plastic crystals of $\left[\left(\mathrm{CH}_{3}\right)_{3} \mathrm{~N}\left(\mathrm{CH}_{2} \mathrm{Cl}\right)\right] \mathrm{FeCl}_{4}(\mathbf{1})$ and $\left[\left(\mathrm{CH}_{3}\right)_{3} \mathrm{~S}\right] \mathrm{FeCl} \mathrm{Fl}_{4}(\mathbf{2})$ following the procedure reported in the literature (see $\mathrm{SI}$ for further details).22,23 The purity and crystallinity of the obtained samples were confirmed by comparison of the acquired powder X-ray diffraction patterns (Fig. S1 and S2 of SI) with the patterns simulated from single-crystal X-ray diffraction data. ${ }^{22,23}$

These samples were studied by differential scanning calorimetry (DSC) at ambient pressure, which showed a first-order phase transition for each of these compounds (Figure S3 and S4 of SI). Compounds (1) and (2) display a phase transition at $T_{\mathrm{t}} \sim 326 \mathrm{~K}$ and $T_{t} \sim 315 \mathrm{~K}$ on heating, with a thermal hysteresis of $\sim 4 \mathrm{~K}$ and $\sim 13 \mathrm{~K}$, respectively. Latent heat and entropy change were obtained by the integration of the peaks in heat flow. The resulting values were $\left|Q_{0}\right|=46 \pm 1 \mathrm{~kJ} \mathrm{~kg}^{-1}$ and $|\Delta S|=140 \pm 1 \mathrm{~J} \mathrm{~kg}^{-1} \mathrm{~K}^{-1}$ for compound (1), and $\left|Q_{0}\right|=40 \pm 1 \mathrm{~kJ} \mathrm{~kg}^{-1}$ and $|\Delta S|=130 \pm 1 \mathrm{~J} \mathrm{~kg}^{-1} \mathrm{~K}^{-1}$ for compound (2). These large thermal changes are in fully agreement with the literature, and they are related to an increase in the structural disorder from a crystalline phase (Figure 1) towards a plastic crystal state. 22,23
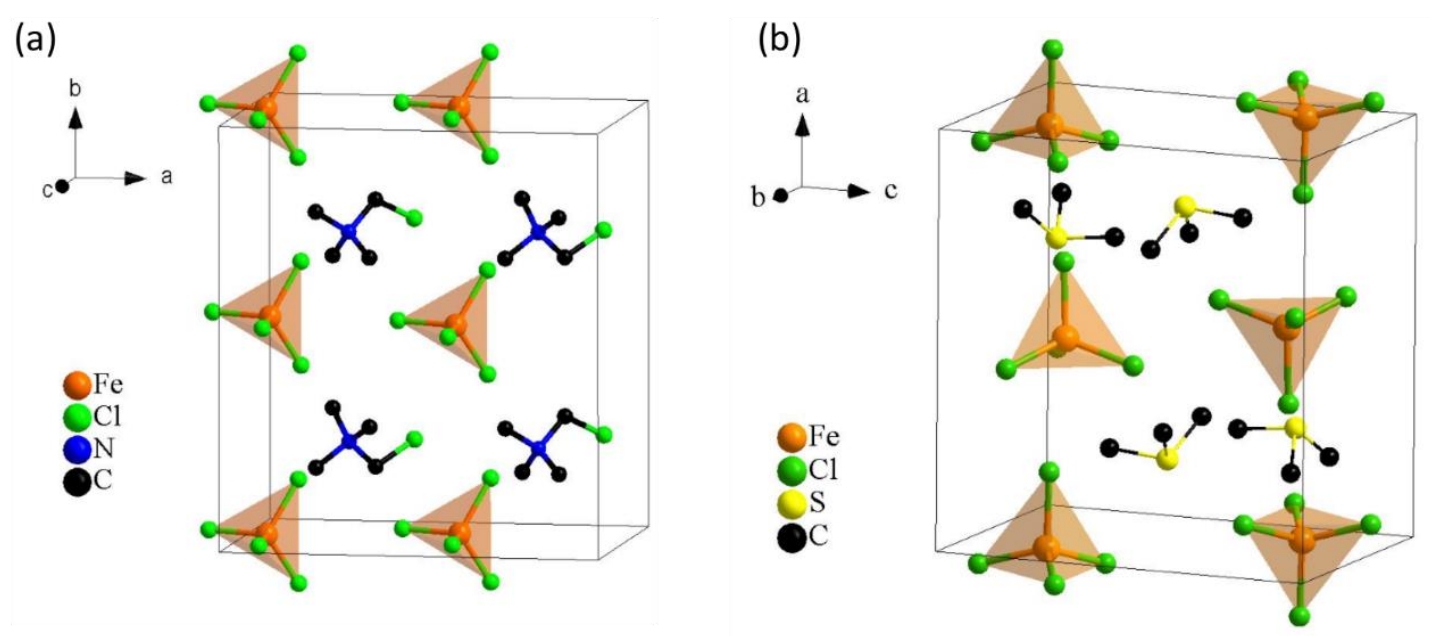

Figure 1. Crystal structure of the low-temperature polymorphs of (a) $\left[\left(\mathrm{CH}_{3}\right)_{3} \mathrm{~N}\left(\mathrm{CH}_{2} \mathrm{Cl}\right)\right] \mathrm{FeCl}$ (1) and (b) $\left[\left(\mathrm{CH}_{3}\right)_{3} \mathrm{~S}\right] \mathrm{FeCl}{ }_{4}(\mathbf{2})$.

Additionally, in order to study the barocaloric properties of these ionic plastic crystals, we carried out DSC analysis at different pressures (Figure 2). In compound (1), the pressure increase shifts the transition temperature towards higher values according to a barocaloric coefficient ${ }^{13}$ of $\mathrm{d} T / \mathrm{d} p \sim 19.7 \mathrm{~K} \mathrm{kbar}^{-1}$ (Figures $\mathbf{2 a}$, b) This is consistent with an enhanced stability of the more ordered and lower volume LTphase at the expense of the more disordered HT-phase due to pressure. On the other hand, in compound (2) the transition temperature on cooling shifts towards higher values with a value of $\mathrm{d} T / \mathrm{d} p \sim 19.9 \mathrm{~K} \mathrm{kbar}^{-1}$. Interestingly, $T_{\mathrm{t}}$ on heating shows inertia towards pressure and remains pressure-independent up to 300 bar. Meanwhile for pressures above 300 bar, $T_{\mathrm{t}}$ moves to higher values with a barocaloric coefficient similar to that of the cooling ramp $\left(\mathrm{d} T / \mathrm{d} p \sim 19.9 \mathrm{~K} \mathrm{kbar}^{-1}\right)$, see Figure $\mathbf{2 c}$, d. This is an anomalous phenomenon (whose origin will be further explored in future publications) that decreases the thermal hysteresis from $13 \mathrm{~K}$ at ambient pressure down to $6 \mathrm{~K}$ from 300 bar upward. Therefore, in compound (2), the thermal losses due to the hysteresis would be reduced at higher pressures. These findings will encourage to further study the origin of this pressure inertia using specific characterization techniques (which are not the scope of the present studies), in order to stablish new mechanism to reduce the thermal hysteresis.

It is worth noting that the barocaloric coefficients of compounds (1) and (2), although smaller than those reported for 1-haloadamantanes and hybrid perovskites, are still larger than for most of barocaloric organic plastic crystals (see Table 1). ${ }^{17,18,20}$ 

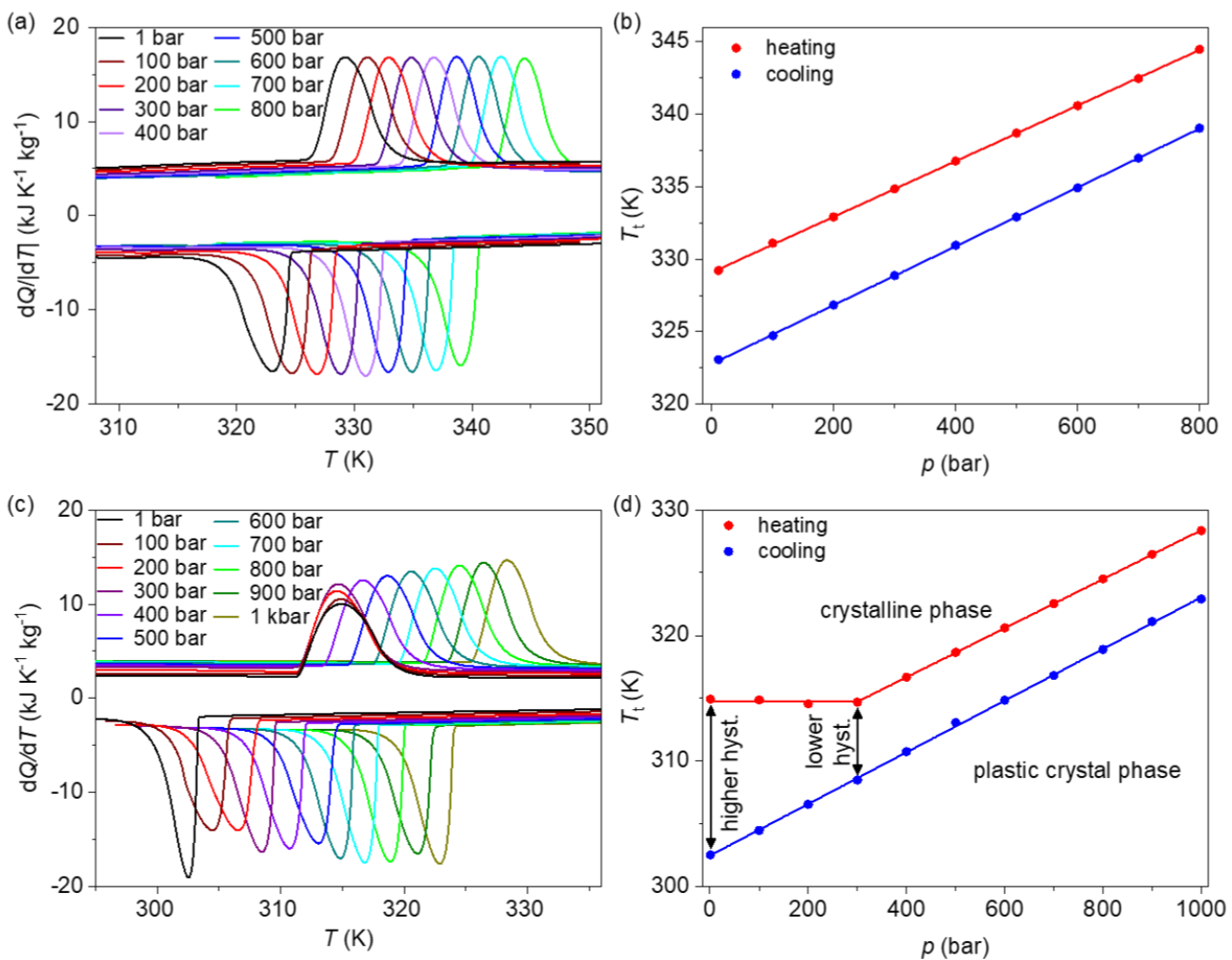

Figure 2. Calorimetric curves of $d Q /|d T|$ versus $T$ at different pressures for compounds (a) $\left[\left(\mathrm{CH}_{3}\right)_{3}\left(\mathrm{ClCH}_{2}\right) \mathrm{N}\right] \mathrm{FeCl}_{4}$ (1) and (b) $\left[\left(\mathrm{CH}_{3}\right)_{3} \mathrm{~S}\right] \mathrm{FeCl} l_{4}$ (2). Transition temperature versus pressure for (b) $\left[\left(\mathrm{CH}_{3}\right)_{3}\left(\mathrm{ClCH}_{2}\right) \mathrm{N}\right] \mathrm{FeCl}_{4}(\mathbf{1})$ and $(\mathrm{d})\left[\left(\mathrm{CH}_{3}\right)_{3} \mathrm{~S}\right] \mathrm{FeCl}_{4}(\mathbf{2})$, identified using the peak in the $\mathrm{d} Q /|\mathrm{d} T|$ curves. Note: the thermal hysteresis of compound (2) gets reduced for $p>300$ bar.

Using these calorimetric data, we have estimated the barocaloric effect in terms of isothermal entropy change by quasi-direct methods, $\Delta S_{\text {it(q-d) }} .{ }^{24}$ For this purpose, isobaric entropy changes $\left(\Delta S_{i b}\right)$ were calculated for each pressure by integrating the heat flow $d Q /|d T|$ over temperature curves (Fig. S5 and 6 of SI). The obtained data shows that, across the phase transition, the value of the isobaric entropy changes $\left(\Delta S_{i b}\right)$ increases up to a plateau of $\left|\Delta S_{i b}\right| \sim 131 \mathrm{~J} \mathrm{~kg}^{-1} \mathrm{~K}^{-1}$ and $\left|\Delta S_{\mathrm{ib}}\right| \sim 126 \mathrm{~J} \mathrm{~kg}^{-1} \mathrm{~K}^{-1}$ for compounds $\mathbf{1}$ and $\mathbf{2}$, respectively. It is worth noting that this maximum value is independent of the applied pressure for compound $\mathbf{2}$, while for compound $\mathbf{1}$ it slightly decreases with pressure (from $\sim 131 \mathrm{~J} \mathrm{~kg}^{-1} \mathrm{~K}^{-1}$ at 1 bar down to $110 \mathrm{~J} \mathrm{~kg}^{-1} \mathrm{~K}^{-1}$ at $800 \mathrm{bar}$ ).

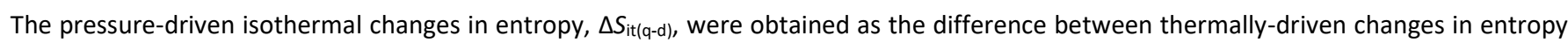
at two different pressures, $\Delta S_{\mathrm{ib}}$, with the following equation (1):

$$
\left.\Delta S_{\text {it(q-d) }}=\Delta S_{\text {ib }}(p \neq 1, T)-\Delta S_{\text {ib }}(p=1, T) \quad \text { (eq. } 1\right)
$$
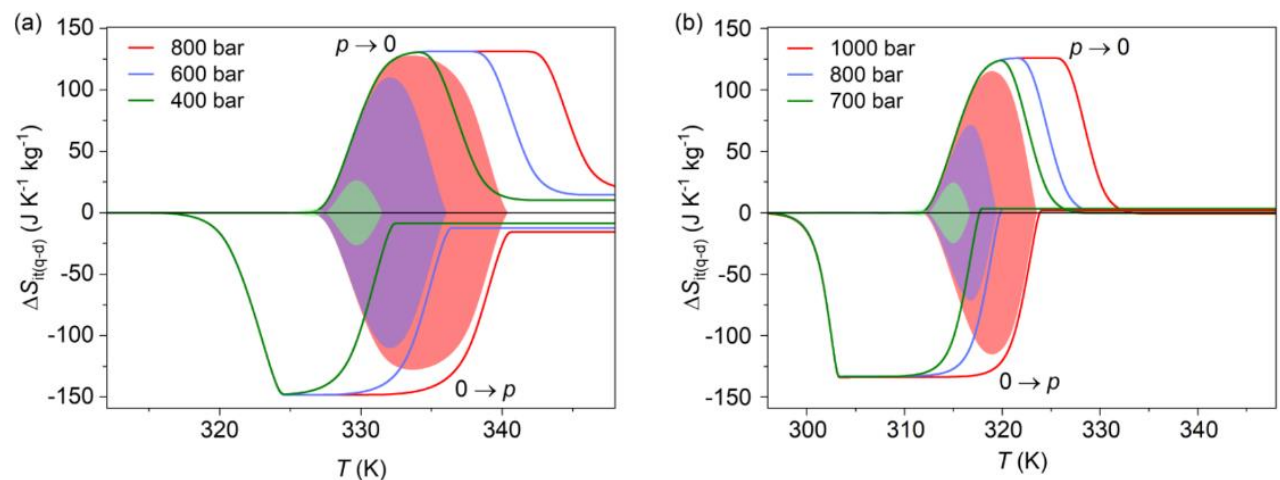

Figure 3. Pressure-driven isothermal changes in entropy on applying $(0 \rightarrow p)$ and removing $(p \rightarrow 0)$ selected hydrostatic pressures. The data shaded using different colours represent the reversible barocaloric response at different pressures for the compound (a) $\left[\left(\mathrm{CH}_{3}\right)_{3}\left(\mathrm{ClCH}_{2}\right) \mathrm{N}\right] \mathrm{FeCl}_{4}(\mathbf{1})$ and $(\mathbf{b})\left[\left(\mathrm{CH}_{3}\right)_{3} \mathrm{~S}\right] \mathrm{FeCl} \mathbf{C l}_{4}(\mathbf{2})$.

Interestingly, these results reveal colossal barocaloric effects in the case of compound (1), which can be reversibly reached under pressures as small as 800 bar $\left(I \Delta S_{\text {it(q-d)rev }} \sim 123 \pm 1 \mathrm{~J} \mathrm{~K}^{-1} \mathrm{~kg}^{-1}\right)$. Furthermore, the operating temperature range at this pressure is as large as $13 \mathrm{~K}$. In the case of compound (2), the barocaloric effects are similar $\left(\mid \Delta S_{\text {itt(q-d)rev }} \sim 125 \pm 1 \mathrm{~J} \mathrm{~K}^{-1} \mathrm{~kg}^{-1}\right)$ although require the application of slightly larger 
pressures ( $p=1 \mathrm{kbar}$ ) to induced them reversibly. In this latter material, the operating temperature change is also similar to compound (1), with a value of $7 \mathrm{~K}$ at $1 \mathrm{kbar}$. It should be noted that additional changes in isothermal entropy ${ }^{9}$ that arise due to volumetric thermal expansion were not considered. This is because the coefficient of thermal expansion decreases significantly under pressure in soft materials. ${ }^{12,25}$

In order to confirm the colossal values of the barocaloric effects, we have also studied the entropy changes provoked by pressure under

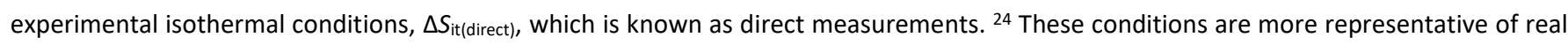
practical applications, where the materials are under continuous pressure cycles. ${ }^{24}$ In that regard, Figure 4 shows the heat flow $d Q /|d p|$ on compression-decompression cycles at different temperatures. The integration of those curves shows that compound (1) displays a value of $\left|\Delta S_{\text {it(direct) }}\right| \sim 147 \pm 1 \mathrm{~J} \mathrm{~K}^{-1} \mathrm{~kg}^{-1}$ at $334 \mathrm{~K}$ and 600 bar. As for compound (2), the observed barocaloric effect is as large as $\left|\Delta S_{\text {it(direct) }}\right| \sim 131 \pm 1 \mathrm{~J} \mathrm{~K}^{-1} \mathrm{~kg}^{-1}$ at $319 \mathrm{~K}$ and 900 bar. It worth noting that these values show a slightly better performance (larger barocaloric effects under smaller pressures) than estimated by quasi-direct methods.
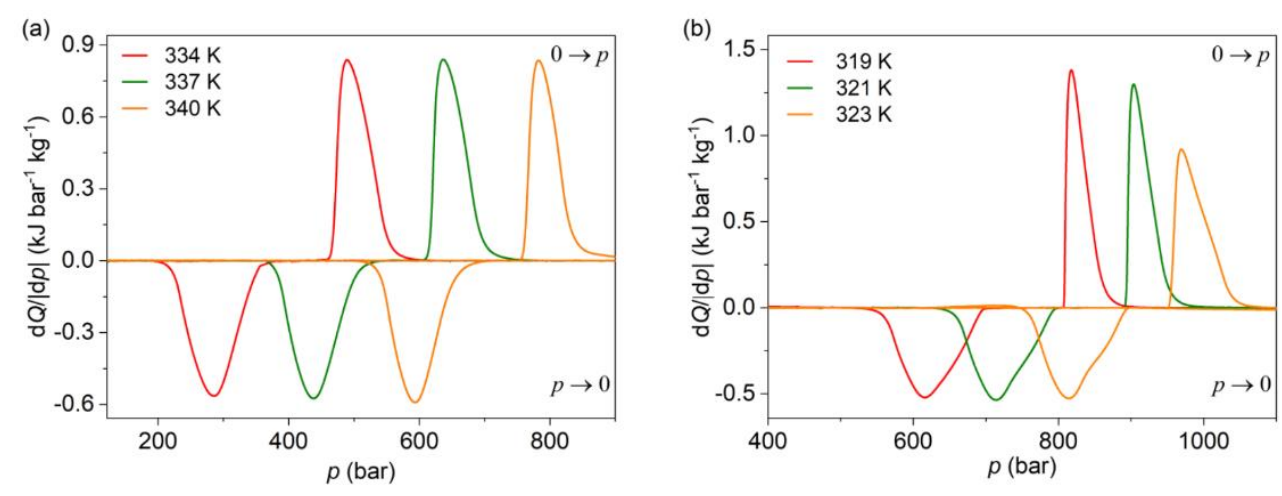

Figure 4. Heat flow $\mathrm{d} Q /|\mathrm{d} p|$ on cycles of applying $(0 \rightarrow p)$ and removing $(p \rightarrow 0)$ hydrostatic pressure at different temperatures for compound (a) $\left[\left(\mathrm{CH}_{3}\right)_{3}\left(\mathrm{ClCH}_{2}\right) \mathrm{N}\right] \mathrm{FeCl}_{4}(\mathbf{1})$ and $\left(\right.$ b) $\left[\left(\mathrm{CH}_{3}\right)_{3} \mathrm{~S}\right] \mathrm{FeCl}_{4}$ (2). Note: baseline was subtracted for a better visualization.

For comparison purposes, in Table 1 we compile selected barocaloric parameters of the here reported hybrid ionic plastic crystals in contrast to barocaloric organic plastic crystals and hybrid perovskites. It is important to note that our hybrid ionic plastic crystals can reach reversible colossal barocaloric effects under pressures much smaller than organic plastic crystals, such as neopentylglycol (NPG), pentaglycerine (PG) and neopentylalcohol (NPA). ${ }^{17,18}$ Furthermore, these colossal effects are much larger than those exhibited by hybrid perovskites or the fullerite plastic crystal. ${ }^{12,13,15,26}$

Table 1. Selected barocaloric parameters of hybrid ionic plastic crystals in comparison with purely organic plastic crystals and hybrid organicinorganic perovskites. $T_{h}=$ transition temperature on heating; $T_{c}=$ transition temperature on cooling; $\mathrm{d} T / \mathrm{d} p=$ average barocaloric coefficient; $\left|\Delta S_{\text {rev }}\right|=$ reversible barocaloric effects obtained from quasi-direct methods in mass and volume units, respectively; $\Delta p=$ applied pressure required to induce the aforementioned reversible barocaloric effect; $\left|\Delta S_{\text {rev }}\right| / \Delta p=$ barocaloric strength in mass and volume units respectively; $\rho=$ materials density, $T_{o p}=$ operating temperature range.

\begin{tabular}{|c|c|c|c|c|c|c|c|c|c|c|c|}
\hline Compound & $\begin{array}{r}T_{h} \\
(\mathrm{~K})\end{array}$ & $\begin{array}{r}T_{c} \\
(\mathrm{~K})\end{array}$ & $\begin{array}{c}\mathrm{d} T / \mathrm{d} p \\
\left(\mathrm{~K} \mathrm{kbar}^{-1}\right)\end{array}$ & $\begin{array}{c}\left|\Delta S_{\text {rev }}\right| \\
\left(\mathrm{J} \mathrm{K}^{-1} \mathbf{k g}^{-1}\right)\end{array}$ & $\begin{array}{c}\left|\Delta S_{\text {rev }}\right| \\
\left(\mathrm{J} \mathrm{K}^{-1} \mathbf{I}^{-1}\right)\end{array}$ & $\begin{array}{c}\Delta p \\
\text { (bar) }\end{array}$ & $\begin{array}{c}\left|\Delta S_{\text {rev }}\right| / \Delta p \\
\left(\mathrm{~J} \mathrm{~K}^{-1} \mathrm{~kg}^{-1} \mathrm{kbar}^{-1}\right)\end{array}$ & $\begin{array}{c}\left|\Delta S_{\text {rev }}\right| / \Delta p \\
\left(\left.\mathrm{~J} \mathrm{~K}^{-1}\right|^{-1} \mathrm{kbar}^{-1}\right)\end{array}$ & $\begin{array}{c}\rho \\
\left(\mathrm{kg} \mathrm{|}^{-1}\right)\end{array}$ & $\begin{array}{c}T_{\mathrm{op}} \\
\text { at } 1 \mathrm{kbar} \\
(\mathrm{K})\end{array}$ & Other risks \\
\hline$\left[\left(\mathrm{CH}_{3}\right)_{3}\left(\mathrm{ClCH}_{2}\right) \mathrm{N}\right] \mathrm{FeCl}_{4}$ & 326 & 322 & 19.7 & 123 & 196.8 & 800 & 153.8 & 246 & 1.6 & $\begin{array}{c}326-342 \\
(16 \mathrm{~K})\end{array}$ & Non reported \\
\hline$\left[\left(\mathrm{CH}_{3}\right)_{3} \mathrm{~S}\right] \mathrm{FeCl}_{4}$ & 315 & 302 & 19.9 & 125 & 200 & 1000 & 125 & 200 & 1.6 & $\begin{array}{c}315-322 \\
(7 \mathrm{~K})\end{array}$ & Non reported \\
\hline$\left(\mathrm{CH}_{3}\right)_{2} \mathrm{C}\left(\mathrm{CH}_{2} \mathrm{OH}\right)_{2}{ }^{18}$ (NPG) & 311 & 296 & 10.3 & 445 & 445 & 2500 & 178 & 178 & 1.0 & \begin{tabular}{|c|}
- \\
\end{tabular} & Flammable \\
\hline$\left(\mathrm{CH}_{3}\right) \mathrm{C}\left(\mathrm{CH}_{2} \mathrm{OH}\right)_{3}{ }^{17}(\mathrm{PG})$ & 354 & 350 & 8.7 & 490 & 343 & 2400 & 204.2 & 142.9 & 0.7 & $\begin{array}{c}354-359 \\
(5 \mathrm{~K})\end{array}$ & Flammable \\
\hline$\left(\mathrm{CH}_{3}\right)_{3} \mathrm{C}\left(\mathrm{CH}_{2} \mathrm{OH}\right)^{17}(\mathrm{NPA})$ & 231 & 211 & 17 & 290 & 237.2 & 2600 & 111.5 & 91.2 & 0.818 & - & Flammable \\
\hline Fullerite $\mathrm{C}_{60}{ }^{26}$ & 257 & 254 & 17 & 25 & 48.8 & 1000 & 25 & 48.8 & 1.95 & $\begin{array}{c}257-271 \\
(14 \mathrm{~K})\end{array}$ & Non reported \\
\hline $\mathrm{C}_{10} \mathrm{H}_{15} \mathrm{Br}^{20}$ & 316 & 308 & 35 & 134 & 187.6 & 1000 & 134 & 187.6 & 1.4 & $\begin{array}{c}316-343 \\
(27 \mathrm{~K})\end{array}$ & $\begin{array}{l}\text { Potential } \mathrm{HBr} \\
\text { formation }\end{array}$ \\
\hline $\mathrm{C}_{10} \mathrm{H}_{15} \mathrm{Cl} 20$ & 254 & 245 & 27 & 153 & 168.3 & 1000 & 153 & 168.3 & 1.1 & $\begin{array}{c}254-272 \\
(18 \mathrm{~K})\end{array}$ & $\begin{array}{c}\text { Potential } \mathrm{HCl} \\
\text { formation }\end{array}$ \\
\hline$\left[\left(\mathrm{CH}_{3}\right)_{4} \mathrm{~N}\right] \mathrm{Mn}\left[\mathrm{N}_{3}\right]_{3}{ }^{12}$ & 305 & 298 & 12 & 70 & 112.7 & 900 & 77.8 & 125.2 & 1.61 & $\begin{array}{c}305-310 \\
(5 \mathrm{~K})\end{array}$ & Potential explosive \\
\hline$[\mathrm{TPrA}] \mathrm{Mn}[\mathrm{dca}]_{3}{ }^{13}$ & 330 & 329 & 23.1 & 37.0 & 62.9 & 70 & 528.6 & 898.6 & 1.70 & $\begin{array}{c}330-352 \\
(22 \mathrm{~K})\end{array}$ & Non reported \\
\hline$[\operatorname{TPrA}] \mathrm{Cd}[\mathrm{dca}]_{3}{ }^{15}$ & 386 & 385 & 38.2 & 11.5 & 21.6 & 70 & 164.3 & 308.9 & 1.88 & $\begin{array}{c}386-423 \\
(37 \mathrm{~K})\end{array}$ & $\mathrm{Cd}$ is highly toxic \\
\hline
\end{tabular}


On the other hand, when comparing with 1-haloadamantanes, ${ }^{20}$ the barocaloric effects in mass units are similar to the here reported compounds (1) and (2). However, it should be noted that compound (1) and (2) are much denser than organic plastic crystals (due to the presence of inorganic building-blocks) and, therefore, their barocaloric effects in volume units are appreciably larger (Table 1). This is an important advantage for commercial applications, since larger barocaloric effects per unit of volume would imply more compact devices. Accordingly, the reversible barocaloric strength in volume units, $I \Delta S_{\text {rev }} l / \Delta p$, of the hybrid ionic plastic crystals is larger than in any reported barocaloric organic plastic crystal. In addition, up-to-date, the here reported barocaloric hybrid ionic plastic crystals has not shown other risks that has been reported for organic plastic crystals and hybrid perovskites, such as flammability, toxicity, potential explosiveness, or potential formation of corrosive acids.

\section{Conclusions.}

In summary, we report the outstanding barocaloric properties of two hybrid ionic plastic crystals with discrete ionic building-blocks. The weak chemical interactions and the soft nature of the organic cations allow these materials to exhibit a very large pressure responsiveness with remarkable barocaloric coefficients $\left(\mathrm{d} T_{\mathrm{t}} / \mathrm{d} p \sim 20 \mathrm{~J} \mathrm{kbar}^{-1}\right)$ and barocaloric strengths $\left(\left|\Delta S_{\text {rev }}\right| / \Delta p>120 \mathrm{~J} \mathrm{~K}^{-1} \mathrm{~kg}^{-1}\right.$ or $\left.>200 \mathrm{~J} \mathrm{~K}^{-1} \mathrm{I}^{-1}\right)$, similar or even larger than those exhibited by barocaloric organic plastic crystals. Meanwhile, the presence of inorganic anions confers a density similar to that of barocaloric hybrid perovskites, which provides a volumetric barocaloric effect larger than any organic plastic crystal or hybrid perovskite, up to date. Moreover, the hybrid ionic plastic crystals can operate under relatively low pressures and in a large operating temperature range near room temperature. Furthermore, these new barocaloric materials do not show risks associated to the aforementioned barocaloric compounds (which are reported to be flammable, potentially toxic, and/or explosive, or which could form corrosive acids in the presence of fluids with hydroxyl groups). Therefore, this work experimentally demonstrates that hybrid ionic plastic crystals are a new family of promising compounds in the race towards the design of enhanced barocaloric materials for solid-state refrigeration.

\section{Conflicts of interest}

The use of the compounds studied in this work for barocaloric cooling/heating is covered in a recently filed patent application (P202130565) by the same researchers: J. S.-B., J. M. B.-G., E. S.-T., J. G.-B., S. C.-G., M. S.-A., X. M., and M. A. S.-R.

\section{Acknowledgements}

The authors are grateful for financial support from Ministerio de Economía y Competitividad MINECO and EU-FEDER (MAT2017-86453-R), Xunta de Galicia, and ERC Starting Grant no 680032. J.G.B. acknowledges Xunta de Galicia for a Predoctoral Fellowship. J.M.B.G. acknowledges Xunta de Galicia for a Postdoctoral Fellowship. X.M. is grateful for support from the Royal Society.

\section{Notes and references}

$1 \quad$ X. Moya and I. M. llevbare, Henry Royce Inst., 2020.

2 J. M. Calm, Int. J. Refrig., 2008, 31, 1123-1133.

3 Y. T. Ge and S. A. Tassou, Energy Convers. Manag., 2014, 78, 245-252.

4 A. Cavallini, G. Censi, D. Del Col, L. Doretti, G. A. Longo and L. Rossetto, Int. J. Refrig., 2001, 24, $73-87$.

5 J. M. Gonçalves, C. Melo, C. J. L. Hermes and J. R. Barbosa Jr, J. Brazilian Soc. Mech. Sci. Eng., 2011, 33, $159-165$.

6 V. W. Bhatkar, V. M. Kriplani and G. K. Awari, Int. J. Environ. Sci. Technol., 2013, 10, 871-880.

7 A. Greco, C. Aprea, A. Maiorino and C. Masselli, Int. J. Refrig., 2019, 106, 66-88.

8 A. Kitanovski, U. Tomc and A. Poredo, Int. J. Refrig., 2015, 57, 288-298.

9 P. Lloveras, E. Stern-Taulats, M. Barrio, J. L. Tamarit, S. Crossley, W. Li, V. Pomjakushin, A. Planes, L. Mañosa, N. D. Mathur and X. Moya, Nat. Commun., 2015, 6, 8801.

10 M. V Gorev, E. V Bogdanov and I. N. Flerov, J. Phys. D. Appl. Phys., 2017, 50, 384002.

11 C. Aprea, A. Greco, A. Maiorino and C. Masselli, Climate, 2019, 7, 9.

12 J. Salgado-Beceiro, A. Nonato, R. X. Silva, A. García-Fernández, M. Sánchez-Andújar, S. Castro-Garcia, E. Stern-Taulats, M. A. SeñarísRodríguez, X. Moya and J. M. Bermúdez-García, Mater. Adv., 2020, 1, 3167-3170.

13 J. M. Bermúdez-García, M. Sánchez-Andújar, S. Castro-García, J. López-Beceiro, R. Artiaga and M. A. Señarís-Rodríguez, Nat. Commun., 2017, 8, 15715.

A. Aznar, P. Lloveras, M. Romanini, M. Barrio, J. L. Tamarit, C. Cazorla, D. Errandonea, N. D. Mathur, A. Planes, X. Moya and L. Mañosa, Nat. Commun., 2017, 8, 1.

15 J. M. Bermúdez-García, S. Yáñez-Vilar, A. García-Fernández, M. Sánchez-Andújar, S. Castro-García, J. López-Beceiro, R. Artiaga, M. Dilshad, X. Moya and M. A. Señarís-Rodríguez, J. Mater. Chem. C, 2018, 6, 9867-9874. J. M. Bermúdez-García, M. Sánchez-Andújar and M. A. Señarís-Rodríguez, J. Phys. Chem. Lett., 2017, 8, 4419-4423.

17 A. Aznar, P. Lloveras, M. Barrio, P. Negrier, A. Planes, L. Mañosa, N. Mathur, X. Moya and J. L. Tamarit, J. Mater. Chem. A, 2020, 8, 639-647.

18 P. Lloveras, A. Aznar, M. Barrio, P. Negrier, C. Popescu, A. Planes, L. Mañosa, A. Avramenko, N. D. Mathur, X. Moya and J. Tamarit, Nat. Commun., 2019, 10, 1803.

B. Li, Y. Kawakita, S. Ohira-Kawamura, T. Sugahara, H. Wang, J. Wang, Y. Chen, S. I. Kawaguchi, S. Kawaguchi, K. Ohara, K. Li, D. Yu, R. Mole, T. Hattori, T. Kikuchi, S. ichiro Yano, Z. Zhang, Z. Zhang, W. Ren, S. Lin, O. Sakata, K. Nakajima and Z. Zhang, Nature, 2019, 567, 506-510.

A. Aznar, P. Negrier, A. Planes, L. Mañosa, E. Stern-Taulats, X. Moya, M. Barrio, J.-L. Tamarit and P. Lloveras, Appl. Mater. Today, 2021, 23, 101023. P. J. Kropp, G. S. Poindexter, N. J. Pienta and D. C. Hamilton, J. Am. Chem. Soc., 1976, 98, 8135-8144.

22 J. Salgado-Beceiro, J. M. Bermúdez-García, A. L. Llamas-Saiz, S. Castro-García, M. A. Señarís-Rodríguez, F. Rivadulla and M. SánchezAndújar, J. Mater. Chem. C, 2020, 8, 13686-13694. 


\section{Supplementary Information}

\section{Experimental}

The precursor $\left[\left(\mathrm{CH}_{3}\right)_{3}\left(\mathrm{CH}_{2} \mathrm{Cl}\right) \mathrm{N}\right] \mathrm{Cl}$ for the compound 1 was prepared by mixing $\left(\mathrm{CH}_{3}\right)_{3} \mathrm{~N}$ solution (45 wt. \% in $\mathrm{H}_{2} \mathrm{O}$ Sharlab) in an excess of $\mathrm{CH}_{2} \mathrm{Cl}_{2}$ (99\% anhydrous Sigma Aldrich) stirring at room temperature. Crystals of 1 were synthesized by mixing stoichiometric amounts of the precursor $\left[\left(\mathrm{CH}_{3}\right)_{3}\left(\mathrm{CH}_{2} \mathrm{Cl}\right) \mathrm{N}\right] \mathrm{Cl}$ and $\mathrm{FeCl}_{3} \cdot 6 \mathrm{H}_{2} \mathrm{O}(98 \%$ Sigma-Aldrich) and slow evaporation.

Crystals of 2 were obtained by slow evaporation of an aqueous solution containing $\left[\left(\mathrm{CH}_{3}\right)_{3} \mathrm{~S}\right] \mathrm{Br}\left(98 \%\right.$ Sigma-Aldrich) and $\mathrm{FeCl} 3 \cdot 6 \mathrm{H}_{2} \mathrm{O}(98 \% \mathrm{Sigma}-$ Aldrich) in stoichiometric proportion, and an excess of $\mathrm{HCl}$ (ca. $37 \%$ in $\mathrm{H}_{2} \mathrm{O}$ ACS reagent, ACROS Organics).

$X$-ray powder diffraction (XRPD) studies at room temperature were performed in a Siemens D-5000 diffractometer using CuK $\alpha$ radiation $(\lambda=1.5418 \AA$ A). The experimental XRPD pattern was compared with the profile obtained from the single crystal structure, which was generated by the Mercury 3.5.1 software.

Atmospheric and variable-pressure differential scanning calorimetry (DSC) analyses were performed in a Setaram $\mu$ DSC7 EVO microcalorimeter equipped with a pressure pump with nitrogen gas as a pressure-transmitting media. Quasi-direct barocaloric measurements were made for $\sim 100$ $\mathrm{mg}$ of each compound at $\pm 1.2 \mathrm{~K} \mathrm{~min}^{-1}$ and at different isobaric pressures. Direct measurements were carried out with the same amount of sample with $\mathrm{a} \pm 10$ bar $\mathrm{min}^{-1}$ swept in pressure.

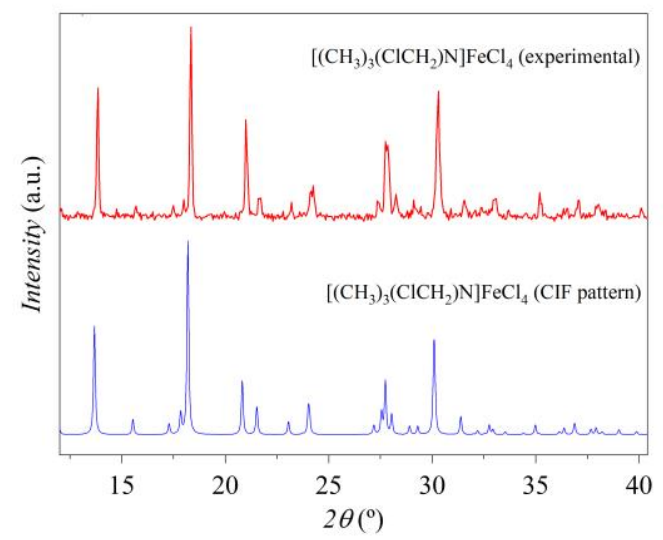

Figure S1. XRPD patterns at room temperature for the as-prepared $\left[\left(\mathrm{CH}_{3}\right)_{3} \mathrm{~N}\left(\mathrm{CH}_{2} \mathrm{Cl}\right)\right] \mathrm{FeCl}_{4}$ compound (red) and the simulated one (blue) based on its single crystal structure at room temperature.

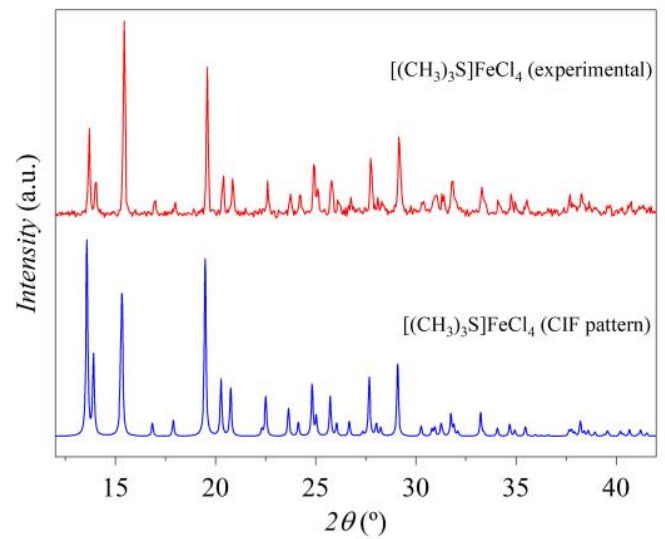

Figure S2. XRPD patterns at room temperature for the as-prepared $\left[\left(\mathrm{CH}_{3}\right)_{3} \mathrm{~S}\right] \mathrm{FeCl}{ }_{4}$ compound (red) and the simulated one (blue) based on its single crystal structure at room temperature. 


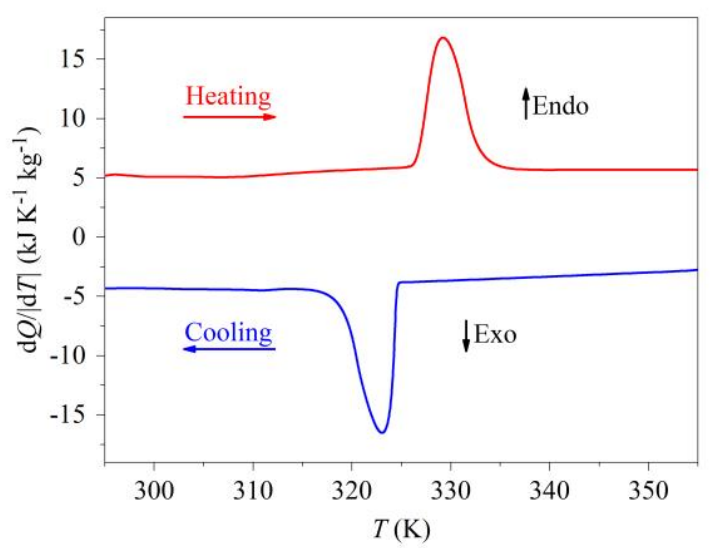

Figure S3. Heat flow $d Q /|d T|$ as a function of temperature at atmospheric pressure for $\left[\left(\mathrm{CH}_{3}\right)_{3} \mathrm{~N}\left(\mathrm{ClCH}_{2}\right)\right] \mathrm{FeCl}_{4}$.

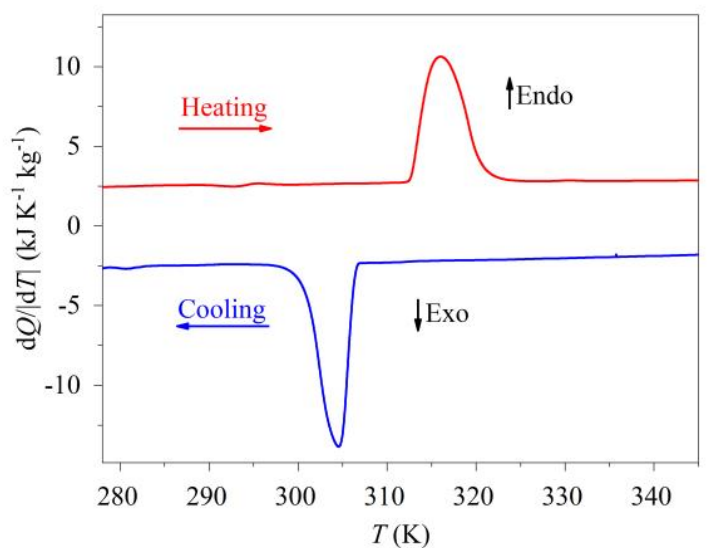

Figure S4. Heat flow $d Q /|d T|$ as a function of temperature at atmospheric pressure for $\left[\left(\mathrm{CH}_{3}\right)_{3} \mathrm{~S}\right] \mathrm{FeCl}_{4}$.

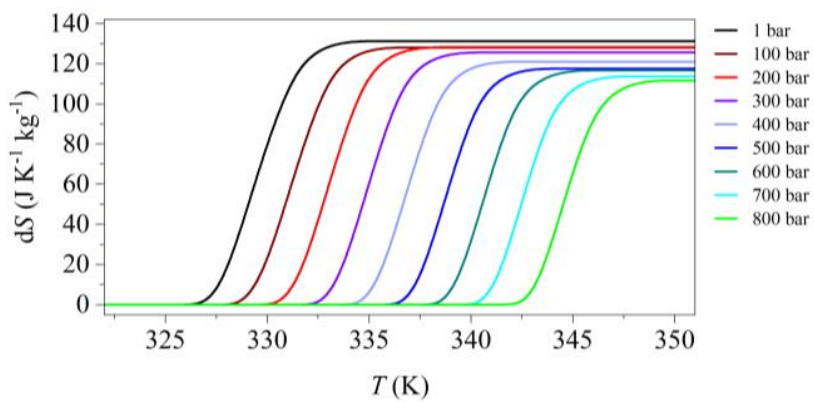

Figure S5. Thermally driven isobaric changes in entropy on heating with respect to the low-temperature phase for each pressure for $\left[\left(\mathrm{CH}_{3}\right)_{3} \mathrm{~N}\left(\mathrm{ClCH}_{2}\right)\right] \mathrm{FeCl}_{4}$.

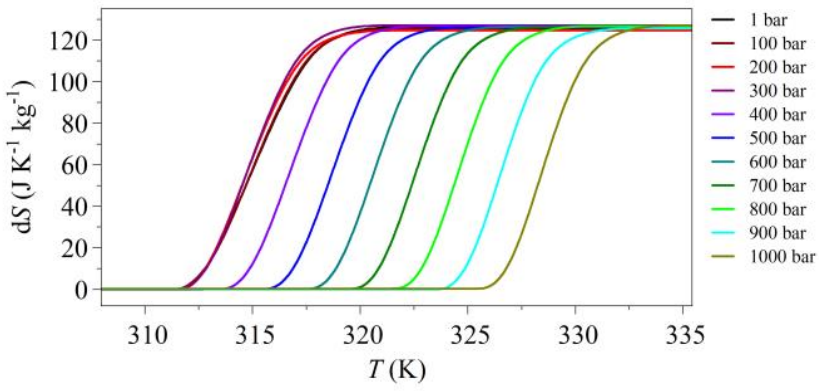

Figure S6. Thermally driven isobaric changes in entropy on heating with respect to the low-temperature phase for each pressure for $\left[\left(\mathrm{CH}_{3}\right)_{3} \mathrm{~S}\right] \mathrm{FeCl}_{4}$. 